\title{
Personal Protective Equipment for Safe Endoscopy: Are we Ready?
}

\author{
Vinay Dhir ${ }^{1}$ \\ ${ }^{1}$ Institute of Digestive and Liver Care (IDL Care), SL Raheja Hospital, \\ Mumbai, Maharashtra, India
}

J Digest Endosc 2020;11:53-54

The novel coronavirus disease (COVID-19) has spread with a breath-taking speed to involve 210 countries and territories, infecting more than 2.7 million people and killing more than 190,000 people, in a short span of 4 months. This rapid spread of a new virus with no previous human exposure has understandably found much of the world unprepared and scrambling to meet the challenge. Our understanding of this particular virus (SARS- COV-2) and its pathophysiology, clinical effects, and treatment is still incomplete. A recent National Institutes of Health guideline has stated that currently there is no preexposure prophylaxis, postexposure prophylaxis, effective treatment, or vaccine for this virus, although lot of work is taking place in this arena. ${ }^{1}$ In the relative absence of knowledge about this virus, experts have fallen back upon experience with previous coronavirus epidemics like the SARS epidemic of 2003. Most of the expert guidelines from various societies have replicated the guidelines issued for SARS epidemic, and this includes endoscopy societies around the world. ${ }^{2,3}$

One aspect of COVID-19 infection that became obvious in the early studies from China, ${ }^{4}$ and confirmed by other countries, was the disproportionately high infection and mortality rates among health care workers. This has prompted guidance about utilization of barrier practices including personal protective equipment (PPE) for health care workers. According to the World Health Organization news bulletin, there were 22,073 infected health care workers as of April 8, and even this number is likely to be an underestimate as many countries do not segregate cases according to profession. While there are no reports of transmission of COVID-19 infection following endoscopy, it is logical to assume such as transmission as endoscopy is an aerosol generating procedure, and the virus has been found in stomach and colon of infected patients. An article in this issue by Philip et al describes how to appropriately utilize PPE. ${ }^{5}$

While PPE use is strongly recommended for endoscopists, there are several issues of concern. First, PPE are a scarce commodity currently, as the entire world needs it and the supplies are much smaller than demand. Till the supply situation improves, it is prudent to triage the endoscopy patients on 1 or
Address for correspondence Vinay Dhir, MD, DNB, FASGE, Institute of Digestive and Liver Care (IDL Care), SL Raheja Hospital, Mumbai, Maharashtra 400016, India (e-mail: vinaydhir@gmail.com).

2 days a week to save on the number of PPEs utilized. Of course, this cannot apply to a patient who needs emergency endoscopy for gastrointestinal (GI) bleed and cholangitis. It is also prudent to limit the number of persons in the endoscopy room to the minimum. The endoscopist, GI assistant, anesthetist, and a nurse should be the maximum personnel allowed for any procedure. All these people should know the right method of donning and doffing the PPE, as infection is possible especially during doffing. Charts displaying the correct methods should be displayed in the endoscopy room. It is also advisable to create separate teams working alternate weeks so that in the unfortunate event of someone getting infected, the endoscopy services should not collapse.

A second and equally important issue is quality control of PPE. Substandard masks and PPE equipment are unfortunately common, and the endoscopy team should be provided with optimum equipment with appropriate certification. N95 masks should have the NIOSH mark on it. PPE should ideally have a CE or equivalent certification. In pandemic situations, quality control often suffers and endoscopists should be vigilant about this aspect.

The third issue is precautions other than PPE. Utilization of PPE is only effective if performed along with other safe practices like hand wash, safe distancing, and appropriate disinfection of scopes and accessories. Most of us do not have the luxury of negative pressure endoscopy rooms, but much can be gained by spacing the procedures, and cleaning the room and surfaces with a disinfectant between procedures, and fumigation once a week.

The fourth issue is cost. Safety comes at a cost and appropriate precautions are likely to have an impact on cost of endoscopy procedure. Patients should be explained the necessity of PPE and the benefits of a safe endoscopy with a negligible chance of transmission either way.

These are challenging times and most likely will change the way we practice endoscopy. An endoscopist is a part of the wider community and infection may occur outside the endoscopy area also. Adequate precautions are necessary in general and also in the endoscopy area. Safety first is the most important principle and appropriate PPE utilization will go a long way in achieving this goal.
DOI https://doi.org/ 10.1055/s-0040-1712340 ISSN 0976-5042.
License terms

(요 (1) $\ominus \circledast$ 


\section{Conflict of Interest}

None declared.

\section{References}

1 Available at: https://www.covid19treatmentguidelines.nih.gov. Accessed April 27, 2020

2 Muscarella LF. Recommendations for the prevention of transmission of SARS during GI endoscopy. Gastrointest Endosc 2004;60(5):792-795
3 Ong J, Cross GB, Dan YY. Prevention of nosocomial SARS-CoV-2 transmission in endoscopy: international recommendations and the need for a gold standard. Gut 2020;gutjnl-2020-32115410.1136/gutjnl-2020-321154

$4 \mathrm{Wu} \mathrm{Z}$, McGoogan JM. Characteristics of and important lessons from the coronavirus disease 2019 (COVID-19) outbreak in China. Summary of a report of 72314 cases from the Chinese Centre for Disease Control and Prevention. JAMA 2020;10.1001/jama/2020.2648

5 Phillip M, Shibi M. Personal Protective Equipment (PPE) during Endoscopy. J Diges Endosc. 2020;11;45-52 